\title{
Lâminas em alto-relevo para ensinar fenômenos ondulatórios a deficientes visuais
}

\author{
High-Relief Sheets for teaching ondulatory phenomena to visual deficients \\ Alexandre Chaves da Silva ${ }^{1}$, Carlos Alberto dos Santos ${ }^{*}[0$ \\ ${ }^{1}$ Escola Estadual de Ensino Profissionalizante Monsenhor Expedito da Silveira de Sousa, Camocim, CE, Brasil \\ ${ }^{2}$ Universidade Federal Rural do Semiárido, Centro de Ciências Exatas e Naturais, Mossoró, RN, Brasil
}

Recebido em 27 de Março, 2018. Revisado em 27 de Abril, 2018. Aceito em 03 de Maio, 2018.

\begin{abstract}
Apresenta-se neste trabalho o planejamento, a elaboração e a testagem de um produto educacional intitulado Lâminas em Alto Relevo para o Ensino de Ondas e Fenômenos Ondulatórios a Deficientes Visuais. Quarenta e sete Lâminas em alto relevo foram confeccionadas em material plástico, com o uso de punções comerciais do tipo punção de centro de $5 \mathrm{~mm}$ (utilizada para o contorno das imagens), PZ1 (utilizada para representação de curvas) e T10 (utilizada para salientar pontos ou estruturas diferentes das anteriores). Foi abordado o conteúdo básico do que se costuma denominar ondulatória nos livros didáticos do ensino médio. O produto foi testado em dez aulas de uma hora e quarenta minutos, ministradas a um deficiente visual total, cujo conhecimento prévio no assunto foi avaliado por meio de um pré-teste com questões do Exame Nacional do Ensino Médio (ENEM). Ao final da testagem, a apropriação conceitual do aluno foi avaliada por meio de um pós-teste, com cinco questões extraídas do pré-teste e outras cinco questões também extraídas do ENEM, mas diferentes daquelas usadas no pré-teste. Pelo rendimento do estudante no pós-teste, e pela sua evidente satisfação, externada em diversos comentários, acredita-se que o produto é potencialmente útil para uso em larga escala.
\end{abstract}

Palavras-chave: Ensino de Física, Ondas, Fenômenos Ondulatórios, Deficiente Visual, Método Braille.

It will be presented in this paper, the elaboration and testing of an educational product entitled High-Relief Sheets for Teaching Waves and Ondulatory Phenomena to Visual Deficients. Forty-seven high-relief sheets were made of plastic material with the use of commercial punches like center punch of $5 \mathrm{~mm}$ (used for the contour of the images), PZ1 (used for curves representation) and T10 (used to emphasize points or structures different from the previous ones). The basic content of what is usually called ondulatory in the textbooks of high school was covered. The product was tested in ten one-hour and forty-minute classes given to a totally visual impaired student, whose prior knowledge of the subject was evaluated through a pre-test with questions from the National High School Examination (ENEM, in Portuguese). At the end of the test, the student's conceptual appropriation was evaluated through a post-test, with five questions extracted from the pre-test and five other questions also extracted from the ENEM, but different from those used in the pre-test. From the student's post-test performance, and from his evident satisfaction, expressed in several comments, it is believed that the product is potentially useful for large-scale use.

Keywords: Physics Teaching, Waves, Ondulatory Phenomena, Visual Deficients, Braille Method.

\section{Introdução}

A necessidade de um produto educacional como o que se apresenta neste trabalho ficou evidente quando em 2016, um dos autores (ACS) foi professor de um deficiente visual possuidor de rara capacidade intelectual. Naquele período lhe foi ensinado termologia e ondas, com os recursos disponíveis na escola para alunos com deficiência visual, e com a sistemática improvisada usualmente utilizada em muitas escolas. Ou seja, usávamos palitos e fazíamos colagem de barbante em papel. Usávamos também o multiplano, um recurso didático utilizado com alguma frequência $[1,2]$

*Endereço de correspondência: cas.ufrgs@gmail.com
Após a realização da edição 2016 do Exame Nacional do Ensino Médio (ENEM), o aluno declarou que havia respondido mais de 20 questões na prova de conhecimentos de Ciências da Natureza e suas tecnologias sem a devida análise por causa da insuficiência do tempo e pela inexperiência do ledor que o auxiliara. No detalhamento de seu relato, explicou que seu ledor apresentava muita dificuldade para ler e interpretar as questões envolvendo gráficos, tabelas e outros tipos de imagens.

Instigados por esse depoimento, fizemos um levantamento bibliográfico e tomamos conhecimento dos trabalhos publicados pelo Prof. Eder Camargo [3-5], que perdeu sua visão ainda jovem, e que confeccionou várias maquetes para o ensino de diferentes tópicos de física. Todavia, são dispositivos de grande volume que dificul- 
tam sua mobilidade e não resolvem o problema referente a exames como o ENEM. Excetuando a considerável produção do Prof. Eder Camargo, são raras as iniciativas nacionais no sentido de prover o sistema educacional de recursos didáticos para deficientes visuais na área da física [6-8].

A alternativa que nos pareceu mais natural, em termos de reprodutibilidade e acessibilidade foi inspirada no método criado na França por Louis Braille, em 1829, adotado no Brasil desde 1856 [9], e conhecido como código alfanumérico Braille, ou simplesmente Método Braille (MB).

O MB é um sistema universalmente reconhecido como excelente para o acesso a textos, mas ainda não permite o acesso a elementos gráficos. Ao longo do tempo essa limitação tem sido enfrentada de diversas maneiras. Em 1999, pesquisadores do Departamento de Física da Universidade Purdue usaram a curva francesa e massas de modelar para produzir recursos didáticos táteis, com os quais ensinaram a uma aluna cega conceitos físicos relacionados com a reta, a parábola, a elipse e o círculo[10]. Alguns anos depois, surgiram no Brasil os trabalhos já citados nos parágrafos acima [3-6]. Embora sejam contribuições relevantes no contexto do ensino de Física no Brasil, os materiais desenvolvidos por Camargo [4] apresentam restrições de mobilidade, e a proposta de Azevedo e Santos [6] refere-se mais a uma abordagem pedagógica do que à fabricação de recursos táteis.

Material educacional tátil é importante para deficientes visuais não apenas no processo de ensino-aprendizagem, como também nos momentos de avaliação como o Exame Nacional do Ensino Médio (ENEM). Mesmo que o texto do exame seja em Braille, há dificuldades em relação às figuras e gráficos, tão abundantes nas questões das ciências da natureza e Matemática. Nesses casos, o deficiente visual conta com o auxílio de um ledor. Geralmente essa pessoa é um fiscal indicado pela coordenação do exame, e nem sempre está apto para a função de ledor.

Inspirados no MB, vislumbramos a possibilidade de produção de lâminas em alto-relevo para o ensino de física. Como se verá mais adiante, essas lâminas podem ser fabricadas em série para uso continuado de leitores cegos em seus estudos e nos exames. Neste trabalho apresentaremos o primeiro conjunto de lâminas para o ensino de fenômenos ondulatórios, bem como sua utilização com o aluno supra mencionado, deficiente visual total.

Com instrumentos típicos da grafia manual Braille e com instrumentos especialmente desenvolvidos para a confecção de desenhos em alto relevo, elaboramos uma série de lâminas para o ensino de ondas e fenômenos ondulatórios. As lâminas foram confeccionadas em folhas plásticas transparentes, utilizadas em encadernação, um material de fácil obtenção, baixo custo, boa visibilidade ao transcritor, longa durabilidade, pequeno volume e peso, de fácil marcação com punção e com os instrumentos especialmente fabricados e ótima leitura por parte do deficiente visual (DV). Daqui por diante utilizaremos a sigla DV indistintamente com o significado de deficiente visual ou deficiência visual. O significado será definido pelo contexto da redação.

\section{Sobre o método Braille}

Apenas por uma questão de completeza apresentaremos aqui noções do método Braille, uma vez que seu domínio foi indispensável para a implementação do projeto que ora apresentamos. Para uma leitura mais detalhada recomenda-se o livro editado pela Secretaria de Educação Especial do MEC [11].

A unidade básica do método Braille, conhecida como célula Braille é composta de duas colunas, cada uma com três pontos (Figura 1a). A combinação desses pontos forma os símbolos alfanuméricos que conhecemos: as letras do alfabeto, os números e os sinais ortográficos. Por exemplo, a letra A equivale ao ponto 1, mas o "ponto 1" de quem escreve não é o mesmo "ponto 1" de quem lê. Para quem escreve, o "ponto 1" é o número 4 na célula Braille. Ou seja, para que a letra A seja lida através do Método Braille, o número 4 deve ser marcado com alguma ferramenta (geralmente uma máquina Braille), de modo que seja produzida uma protuberância para ser percebida pelo tato. Então, ao marcar o ponto 4 (Figura 1b), uma protuberância é produzida no verso da folha. Ao se inverter esta folha, a marcação aparecerá na posição do ponto 1 (Figura 1c). Seguindo essa mesma lógica, para quem escreve, a letra B é representada pela marcação dos pontos 4 e 5 , que corresponderá aos pontos 1 e 2 para quem lê. O código completo pode ser visto no livro supra mencionado [11] ou na Wikipedia ${ }^{1}$

Essas ilustrações foram apresentadas para destacar o fato de que qualquer elemento gráfico (código de letras ou desenho) para ser acessado pela via do tato deve ser produzido no sentido inverso. É por isso que $(4,5)$ transforma-se em $(1,2)$. Além disso, na redação os textos devem ser escritos da direita para a esquerda, de modo que ao se inverter o meio em que foi produzido a escrita apareça na forma habitual, da esquerda para a direita.

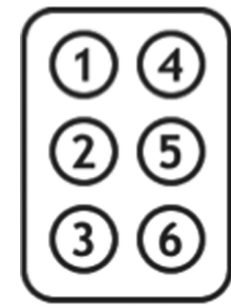

(a)

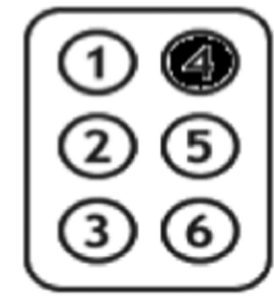

(b)



(c)
Figura 1: (a) Célula Braille; (b) Marcação da letra A; (c) Leitura da letra A. Extraída e adaptada de http://www.aaica.pt/ sservicos/braille.php. Acesso em 5/1/2018.

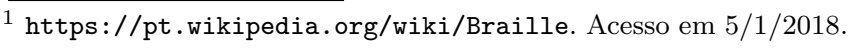




\section{Ferramentas e materiais para a confecção das lâminas}

Pela opção que fizemos de confeccionar lâminas no formato paisagem, tivemos que trabalhar com a reglete, uma vez que as máquinas de escrever códigos Braille só o fazem no formato retrato. Todos os símbolos (letras e gráficos) foram produzidos com punções comerciais: punção de centro de $5 \mathrm{~mm}$ (utilizada para o contorno das imagens), PZ1 (utilizada para representação de curvas) e T10 (utilizada para salientar pontos ou estruturas diferentes das anteriores).

Conforme mencionado acima, as lâminas foram confeccionadas com o plástico transparente utilizado em encadernação, por ser de fácil obtenção, baixo custo, boa visibilidade ao transcritor, longa durabilidade, pequeno volume e peso, fácil perfuração pela punção e ótima lei-

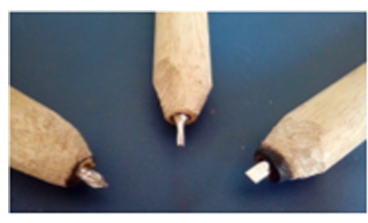

(a)

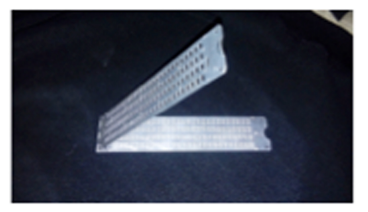

(b) (c)

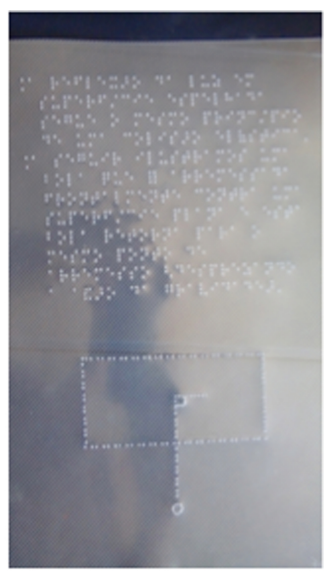

Figura 2: (a) Punções PZ1 (esquerda), P5 (centro) e T10 (direita); (b) Reglete; (c) Lâmina com texto em braile e imagem produzida por um dos autores (ACS). tura ao deficiente visual. A Figura 2 ilustra os materiais utilizados

\section{Produção e utilização do conjunto de lâminas com um estudante cego}

Foram confeccionadas 47 lâminas, uma das quais é exibida na Figura 3. O conjunto de lâminas foi testado com um aluno cego possuidor de excelente capacidade intelectual. Aluno regular de um dos autores (ACS), na Escola Estadual de Ensino Profissionalizante Monsenhor Expedito da Silveira de Sousa (Camocim, CE), obteve 554,1 pontos em Ciências da Natureza e suas Tecnologias e 641,4 em Matemática no ENEM 2017, com apenas os recursos de Ledor e tempo extra de $1 \mathrm{~h}$.

Antes de iniciarmos o desenvolvimento e aplicação do produto, mantivemos contato em três ocasiões com o estudante e sua mãe para definirmos as condições em que o trabalho deveria ser desenvolvido e de que modo o aluno poderia participar. Ficou acertado que teríamos 12 encontros durante a produção do material de modo que o aluno pudesse avaliar a utilidade, as limitações e a validade das lâminas. O primeiro e o último encontros seriam usados para a aplicação de um pré-teste e um pós-teste (Ver Material Suplementar). O pré-teste foi composto de 11 questões, sendo 10 questões de múltipla escolha extraídas do ENEM (2011-2016) e uma questão discursiva: O que você entende por luz? Como podemos definir a cor de um corpo?

O tempo gasto para responder as questões variou entre 82 segundos e 728 segundos, com tempo médio de 334,10 segundos, tempo muito superior à média de 220 segundos, recomendada no ENEM para candidatos com necessidades especiais.

Para garantir a fidelidade no relato daqueles encontros, pedimos permissão ao estudante e a seus responsá-

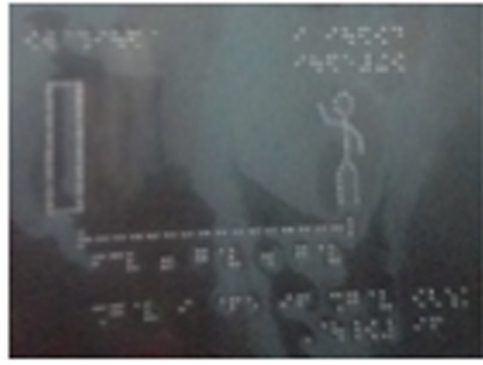

(a)

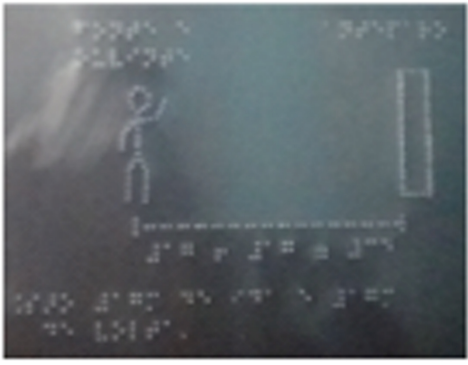

(b)

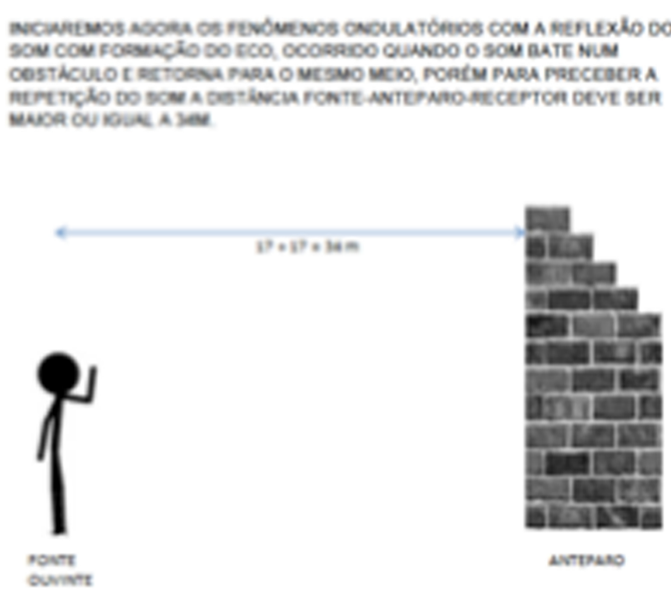

(c)

Figura 3: (a) Lâmina no modo de escrita; (b) Idem, no modo de leitura; (c) Transcrição para o português. 
veis para realizar gravações, que foram cronometradas. Durante os dois testes, cronometramos e registramos o tempo gasto para leitura das questões e imagens, e resolução de cada questão. Os dados obtidos nos testes encontram-se no Material Suplementar.

\section{Encontros com o aluno para testar e aperfeiçoar o produto}

Um sumário dos assuntos tratados nos encontros é apresentado no Quadro 2 do Material Suplementar. Comentaremos a seguir os eventos mais relevantes ocorridos nesses encontros.

Os trabalhos começaram com o conceito de onda, exemplificando-as e reforçando a ideia de que onda não transporta matéria. Para demonstrar o conceito foi usada a lâmina apresentada na Figura 4, com imagem em alto relevo contendo informações apropriadas a um vidente, mas em excesso e complexas para um cego. Então, já no início foi importante a contribuição do aluno, ao apontar a impropriedade daquela lâmina. Era perceptível sua dificuldade em compreender essa imagem. No diálogo que se seguiu ficamos sabendo que ele jamais tivera contato com a ilustração tátil de uma onda. Ficou evidente a e seus elementos definidores. Então, na presença do aluno foi confeccionada uma lâmina com os três tipos de onda apresentados na Figura 5.

Ao tocar nas formas de onda, sobretudo na senoidal, foi notável o entusiasmo do aluno por "visualizar" aquela imagem até então inédita. Imediatamente ele quis saber a respeito do material que lhe possibilitara aquele conhecimento. Sua reação era equivalente à de uma criança

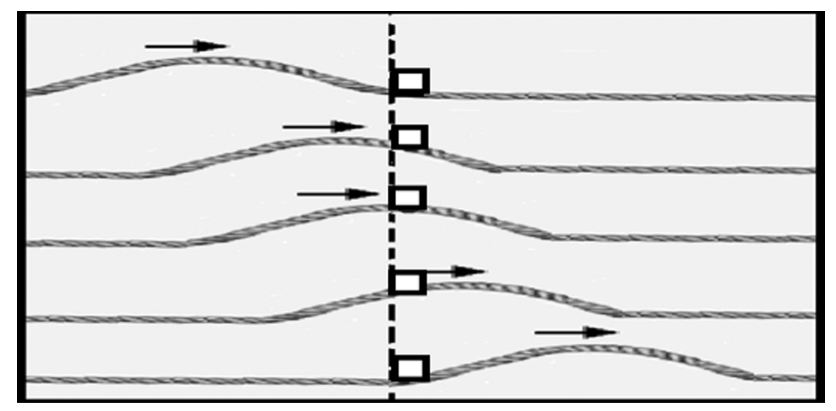

Figura 4: Ilustração para a ideia de que onda não transporta matéria

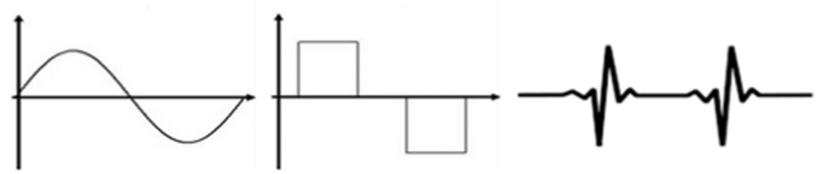

(a)

(b) necessidade do detalhamento dos principais tipos de onda

feliz com um brinquedo novo. Todavia, ele apresentou dificuldade em compreender a onda triangular. Ficou claro que a dificuldade resultava do tamanho dos traços, muito pequenos, e do contorno das curvas, onde os pontos eram mais espaçados do que o necessário para uma boa percepção tátil da continuidade da curva.

Outro problema foi quanto à compreensão da senóide e isto requereu a confecção de lâminas para explicar-lhe a função seno no círculo trigonométrico. Decidimos então encerrar o encontro e retomar o trabalho no encontro seguinte fazendo uma revisão de trigonometria.

Depois dessa revisão apresentamos algumas das principais propriedades de uma onda, tais como classificação quanto à natureza e direção de propagação, direção de vibração das partículas, etc. Por exemplo, o conceito de direção de propagação foi discutido a partir de uma questão do ENEM que aborda a ola, onda espanhola, como exemplo de onda transversal. Mais uma vez, foi cometido o equívoco de apresentar uma imagem com excesso de informação, como a ilustrada na Figura 6 , que deixou o aluno muito confuso. Novamente na presença do aluno, essa imagem foi dividida em partes, cada uma discutindo um aspecto específico do cenário conceitual, como ilustrado na Figura 7.

A Figura 7(a) foi usada na lâmina 4 com a explicação de que na Ola as pessoas, representadas pelos bonecos, fazem o papel de partículas que vibram na direção vertical, subindo e descendo. A Figura 7(b) foi usada na lâmina 5, com a explicação de que na Ola as pessoas realizam o movimento subindo e descendo em sincronia, de modo que para uma onda cuja direção de propagação é da esquerda para a direita (essa direção é indicada na lâmina por uma seta), uma pessoa levanta-se quando a que está à sua direita inicia seu movimento para baixo. Na lâmina 6 as

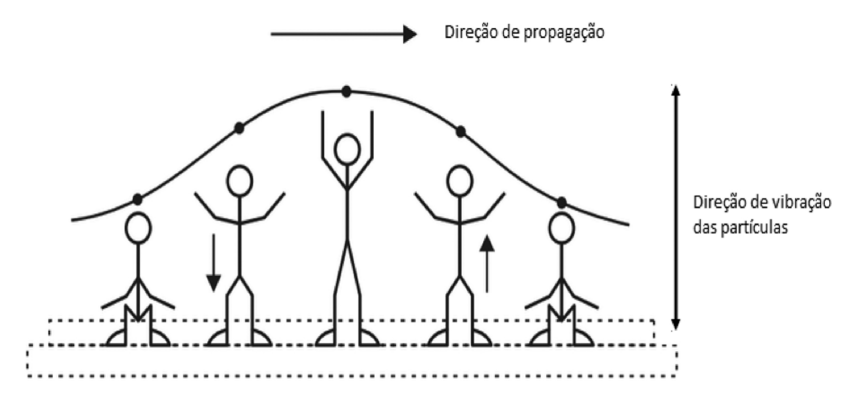

Figura 6: Ola, onda espanhola, para representar a onda transversal.

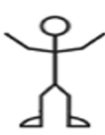

(a)

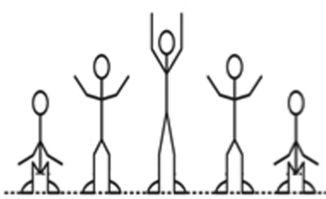

(b)



(c)
Figura 5: Principais tipos de onda: (a) onda senoidal; (b) onda retangular; (c) onda triangular.
Figura 7: Imagens usadas nas lâminas 4, 5 e 6, para discutir a ideia de onda transversal. 
pessoas são substituídas por pontos e a imagem da onda contínua exibida na Figura 7(c) é apresentada, ao lado de setas na vertical, indicativas da direção de movimento das partículas, e na horizontal, indicativas do movimento de propagação da onda.

A Figura 8 registra um momento em que o aluno está fazendo a leitura da lâmina 4 .

Para o caso de onda longitudinal, foi usado o exemplo clássico da onda em uma mola (Figura 9), com a explicação de que neste caso a direção de propagação é paralela à direção de vibração das partículas. Esse movimento de partículas é representado pelas zonas de compressão e depressão na mola.

Além da imagem apresentada na Figura 9, cuja leitura por parte do aluno é ilustrada na Figura 10, usamos o brinquedo mola maluca para ilustrar o conceito de onda longitudinal.

Os temas abordados são de grande complexidade para quem quer que seja, e especialmente para deficientes visu-

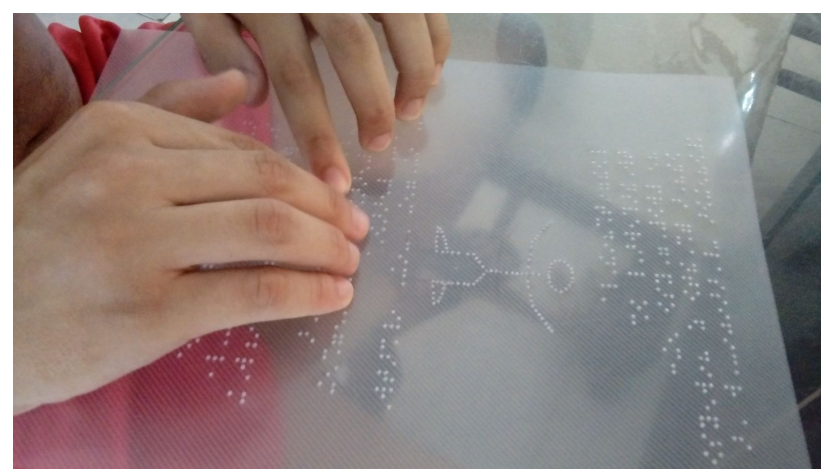

Figura 8: O aluno fazendo a leitura da lâmina 4.

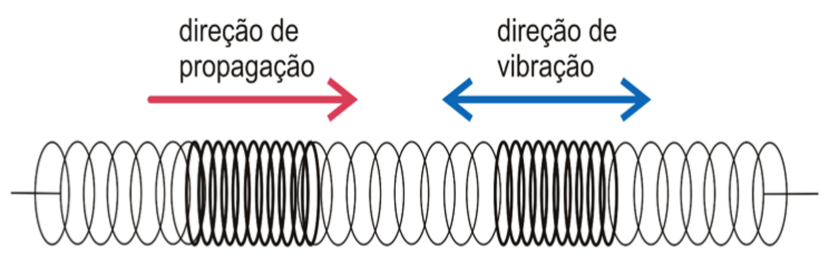

Figura 9: llustração de onda longitudinal.

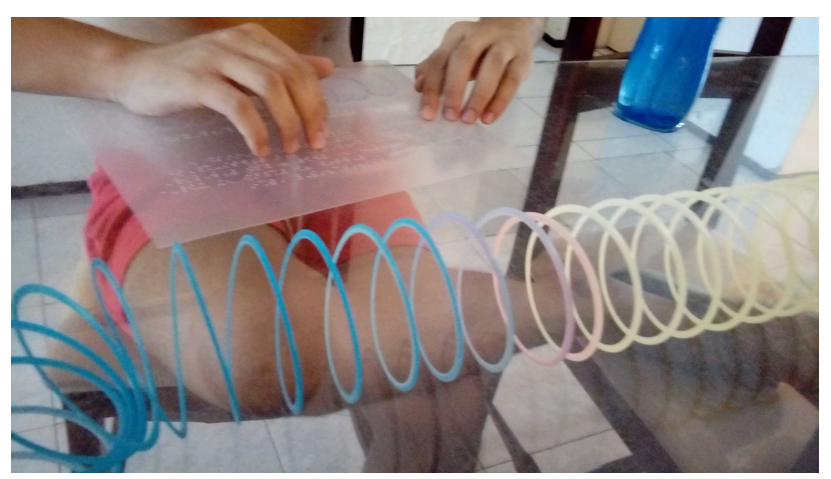

Figura 10: O aluno fazendo a leitura da lâmina 7. À sua frente, o brinquedo mola maluca. ais, na medida em que ilustrações gráficas são essenciais para a apropriação de conceitos tão complexos. Neste sentido, é interessante detalhar os dois últimos encontros de apresentação das lâminas.

Os temas do $10^{\circ}$ encontro, interferência e polarização, estão entre os mais complexos entre os fenômenos ondulatórios tratados no ensino médio. Essa complexidade é potencializada em função da condição visual do aluno. Em função disso foram necessárias oito lâminas (32 a 39 ), iniciando pela figura clássica do experimento de Thomas Young [12], conforme ilustração na Figura 11. No texto que acompanha a imagem, é dito que a partir do experimento da dupla fenda de Thomas Young podemos mostrar uma figura de interferência com padrões bem definidos de amplitudes máximas e mínimas.

A lâmina 33 contém o seguinte texto descrevendo a Figura 11: A imagem ilustra uma onda plana que incide sobre um anteparo com uma fenda (F1) pelo qual a onda sofre difração, esta nova frente de onda formada propaga-se até um outro anteparo com duas fendas (F2) pelo qual sofrerá nova difração, formando assim duas frentes de ondas que se sobrepõem e constroem a figura de interferência.

Para compreender com a devida profundidade a Figura 11, se faz necessária a apropriação de vários conceitos, começando pela superposição de duas ondas, que pode ser construtiva ou destrutiva.

As lâminas 34 a 39 apresentam os fundamentos de interferência e superposição, tais como superposição construtiva e destrutiva, e que esses dois tipos de superposição são apresentados no experimento de Young, sendo os máximos resultantes da superposição construtiva, e os mínimos resultantes da superposição destrutiva.

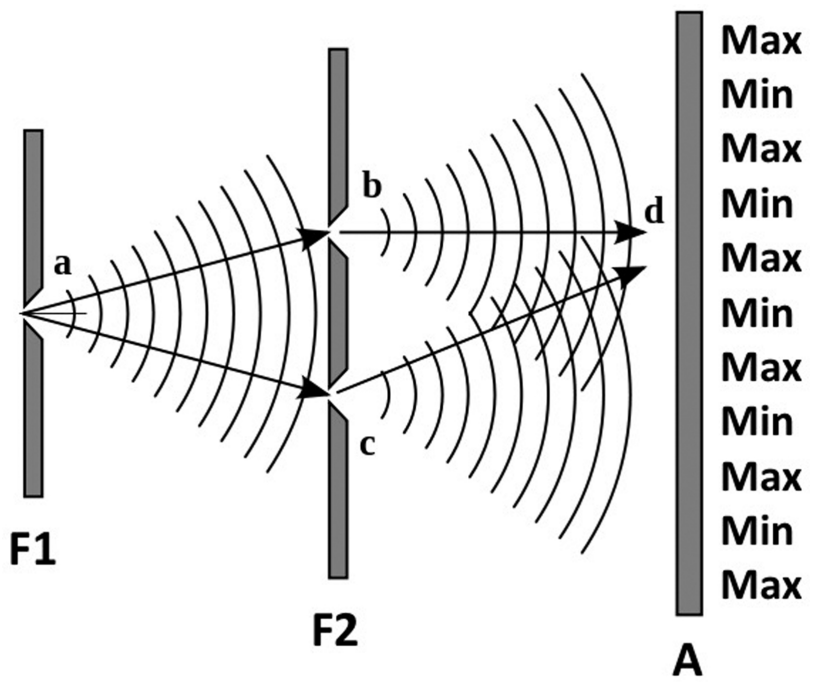

Figura 11: llustração do experimento de dupla fenda de Thomas Young. Adaptado de https://commons.wikimedia.org/ wiki/Category:Doubleslit_experiments\#/media/File: Ebohr1.svg Acesso em 20.02.2018. 
As lâminas 40 a 42 foram usadas para abordar os fundamentos da polarização um assunto especialmente complexo para deficientes visuais, uma vez que há necessidade de imagens tridimensionais. Foi muito difícil transmitir a ideia de polaroide por meio de uma grade, como normalmente é feito nos livros didáticos. Não deve causar qualquer surpresa a afirmativa de que foi perceptível a dificuldade do aluno em compreender o fenômeno da polarização. Para auxiliar sua compreensão, cortamos um plástico em formato de onda senoidal, que ele passou entre os dedos, para simular a ação de uma grade polarizadora (Figura 12).

Finalmente, abordamos o efeito Doppler. Para esse fenômeno o aluno não apresentou dificuldade, pois o mesmo já era do seu conhecimento para o caso de ondas sonoras.

\section{Resultados relevantes}

O objetivo central deste trabalho foi o desenvolvimento de recursos táteis para o ensino de física a deficientes visuais. O objetivo materializou-se na elaboração de um produto educacional, intitulado Lâminas em Alto Relevo para o Ensino de Ondas e Fenômenos Ondulatórios a Deficientes Visuais. Como sugere o título, o conteúdo do produto versa sobre o que geralmente é denominado ondulatória nos livros didáticos do ensino médio.

Para testar e aperfeiçoar o produto, contamos com a colaboração de um aluno com deficiência visual total de nascença. Acredita-se que o sucesso da testagem em muito se deve à notável capacidade intelectual do aluno. Para abordar todo o conteúdo planejado e contido nas 47 lâminas, foram necessários 10 encontros com duração de uma hora e quarenta minutos.

A proficiência do aluno, no assunto pertinente ao produto, foi avaliada por meio de um pré-teste com dez questões de múltipla escolha extraídas do Exame Nacional do Ensino Médio (ENEM) e da questão discursiva: $O$ que você entende por luz? Como podemos definir a cor de um corpo? Após a apresentação do produto, a apropriação conceitual por parte do aluno foi avaliada com um

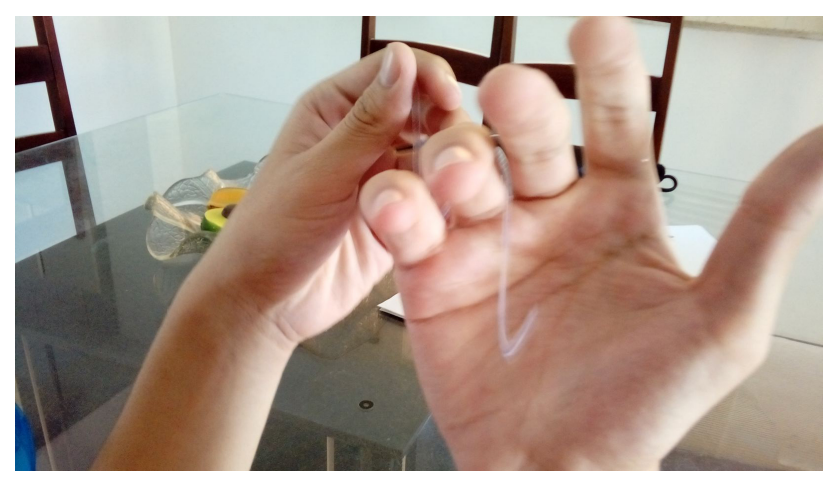

Figura 12: Simulando o efeito de uma grade polarizadora, com uma onda senoidal plástica. pós-teste, contendo 5 questões do pré-teste, 5 questões do ENEM diferentes daquelas usadas no pré-teste e a mesma questão discursiva.

As três questões do pré-teste que necessitaram de mais tempo para a resolução (1, 3 e 5) foram aquelas que contêm imagens. É provável que isso tenha a ver com a dependência do DV na eficácia do ledor para interpretar as figuras. Portanto, supõe-se que figuras táteis como essas aqui propostas auxiliem o DV mais do que o ledor.

Por outro lado, as questões que exigem mais releituras são aquelas que não contêm imagens, excetuando a questão 10 do pós-teste, que exige o cálculo da frequência cardíaca a partir de um eletrocardiograma. Uma questão complexa para videntes e com dificuldade potencializada pela complexa figura a ser interpretada.

Na Figura 13 são apresentadas comparações entre os tempos de resolução das questões comuns aos dois testes. A única questão para a qual o tempo de resolução no pós-teste é superior ao pré-teste é aquela referente ao efeito Doppler (questão 10 no pré-teste e 6 no pós-teste). É bem plausível que esse resultado se deva ao enunciado e às alternativas dessa questão. Além de tratar de um assunto complexo, essa questão apresenta figuras no enunciado e nas alternativas. Durante o pré-teste, a descrição das imagens não o ajudou. Muitas imagens para interpretar e pouco recurso para que ele por si só faça a análise. As várias releituras completas da imagem não o ajudaram. Precisa que seja lido apenas o que interessa para a questão, mas o ledor não pode fazer isso. Outro fator de provável confusão para o aluno é que a linguagem adotada pelo ledor nem sempre corresponde àquela que o aluno ouviu de seu(s) professor(es).

Na questão 6 do pós-teste, com o uso das imagens em alto relevo, o aluno não soube relacionar a mudança de frequência detectada por um observador. Errou a questão porque usou o referencial da fonte e não do observador em repouso. Ou seja, não foi a interpretação das imagens que provocaram o erro. Depois de uma breve explicação ele voltou às alternativas e respondeu de forma correta, analisando tatilmente cada item sem a interferência do professor, comprovando a eficácia das imagens produzidas para esta questão.

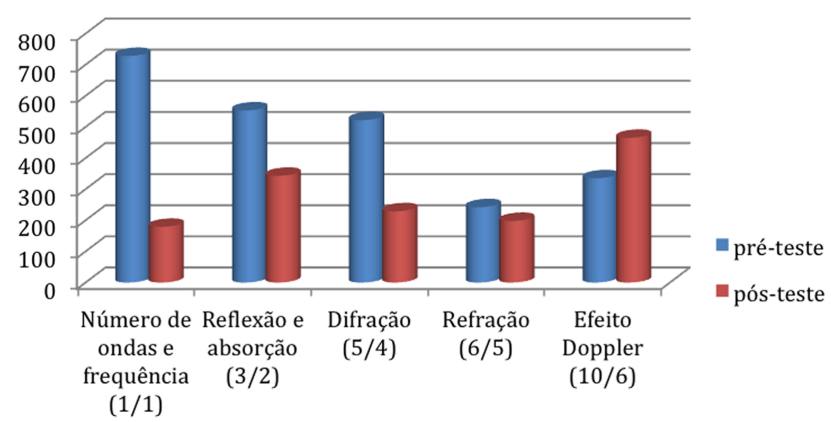

Figura 13: Tempo de resolução (em segundos) das questões comuns aos dois testes. Os números entre parênteses correspondem às questões no pré-teste e no pós-teste, respectivamente. 
O fato de o aluno já ter visto um item anteriormente parece ter tido pouca influência nos resultados. Em alguns casos ele necessitou de releituras e em outros ele cometeu os mesmos erros.

\section{Considerações finais}

Pelos resultados aqui relatados, estamos convencidos de que este produto é potencialmente útil para o ensino de ondas e fenômenos ondulatórios a deficientes visuais, bem como pode inspirar a confecção de produto similar em outras áreas, sobretudo aquelas pertinentes às ciências da natureza.

Acreditamos que a forma artesanal como foi construído esse material, com recursos que desenvolvemos, embora trabalhosa, pode ser facilmente reproduzida por quem se interessar. Por outro lado, ainda não temos uma solução definitiva para produção em série desse material, mas quando estávamos testando o produto, tomamos conhecimento da existência do Monet, um aplicativo para desenhar gráficos com uma impressora Braille. Usar o aplicativo para a produção em série de nosso produto será nosso próximo desafio.

Para professores que desejem usar o produto como aqui apresentado, elaboramos um guia que acompanha as lâminas e está disponível sob demanda aos autores.

Sentimos a falta no mercado de uma reglete que facilite a confecção de imagens em alto-relevo de traços, retas, círculos, retângulos, a partir de punções parecidas com as Goivas para xilogravuras.

Finalmente, estamos convencidos de que as técnicas de transcrição de imagens em alto relevo desenvolvidas ao longo deste trabalho representam um avanço na autonomia de aprendizagem de alunos com deficiência visual. Destacamos o ganho de tempo na interpretação de imagens em função da demarcação dos seus limites e de seu entorno, como outros objetos e eixos direcionais.

\section{Agradecimento}

À CAPES pela bolsa concedida a Alexandre Chaves da Silva, durante a realização do seu Mestrado Nacional Profissional em Ensino de Física, na UFERSA.

\section{Material Suplementar}

O seguinte material suplementar está disponível online:

\section{Pré-teste \\ Pús-ieste.}

Quadro I- Tempo de leitura (TL), tempo de resolução (TR), assunto e tipo de resposta das questões do pré-teste.

Quadro 2 - Sumário dos assuntos tratados nos encontros com o aluno.

Quadro 3 - Tempo de leitura (TL), tempo de resolução (TR), assunto e tipo de resposta das questões do pós-teste.

\section{Referências}

[1] A.S. Fontes, F.A.R. Cardoso e F.V. Ramos, Rev. Thema 9, 1 (2012).

[2] H.B. Silva, A Utilização do Multiplano no Ensino de Geometria Para Alunos do Ensino Fundamental Com Deficiência Visual. Dissertação de Mestrado, Universidade Federal de Goiás, 2015.

[3] E.P. Camargo, Um Estudo das Concepções Alternativas sobre Repouso E Movimento de Pessoas Cegas. Dissertação de Mestrado, Universidade Estadual Paulista, 2000.

[4] E.P. Camargo, Saberes Docentes Para a Inclusão do Aluno com Deficiência Visual em Aulas de Física (Editora UNESP, São Paulo, 2012).

[5] E.P. Camargo, D. Silva e J. Barros Filho, Investig. Em Ensino Ciências 11, 1 (2008).

[6] A.C. Azevedo e A.C.F. Santos, Rev. Bras. Ensino Física 36, 4402 (2014).

[7] J.J.L. Costa, J.R.O. Queiroz e W.W. Furtado, in VIII Encontro Nacional de Pesquisa em Educação em Ciências, Campinas, 2011 (ABRAPEC, Rio de Janeiro, 2011)

[8] A.P. Sonza, Acessibilidade de Deficientes Visuais Aos Ambientes Digitais/virtuais. Dissertação de Mestrado, Universidade Federal do Rio Grande do Sul, 2004.

[9] E.S. Rodrigues, Inclusão Escolar de Pessoas Com Deficiência Visual No Município de Ipatinga (MG): A Perspectiva Dos Alunos E Professores. Dissertação de Mestrado, Universidade Federal de Minas Gerais, 2010.

[10] M. Parry, M. Brazier e E. Fischbach, Phys. Teach. 35, 470 (1997).

[11] MINISTÉRIO DA EDUCAÇÃO. Portaria $n^{\circ} 2.678$, de 24 de setembro de 2002. Brasília, 2002. Disponível em: http://portal.mec.gov.br/seesp/arquivos/pdf/ grafiaport.pdf

[12] C.A. Santos, Os Dez Mais Belos Experimentos da Física, disponível em: https://www.if .ufrgs.br/tex/fis142/ fismod/mod06/m_s06.html, acesso em 20/02/2018. 